\title{
Aspectos sobre a relação entre exercício físico, estresse oxidativo e zinco
}

\author{
Aspects of the relationship between physical \\ activity, oxidative stress and zinc
}

Laiana Sepúlveda de ANDRADE ${ }^{1}$

Dilina do Nascimento MARREIRO²

Este trabalho visa a contribuir com informações sobre a relação entre exercício físico, estresse oxidativo e zinco. A formação de espécies reativas de oxigênio durante o exercício pode contribuir para danos tissulares e celulares, prejudicando o desempenho do atleta. Podem amenizar esses efeitos alguns minerais, como o zinco, que atuam como cofator da enzima superóxido dismutase e na regulação da síntese da metalotioneína, proteínas importantes no sistema de defesa antioxidante. No exercício físico, ocorrem distúrbios na compartimentalização do zinco, com alterações da concentração desse mineral em compartimentos celulares. No entanto, os mecanismos envolvidos no comportamento metabólico do zinco bem como a participação do mineral na melhora do desempenho físico ainda não estão totalmente esclarecidos. Dessa forma, conclui-se que a distribuição do zinco em organismos submetidos ao estresse oxidativo e os efeitos da deficiência desse mineral na capacidade antioxidante durante o exercício ainda devem ser pesquisados mais profundamente.

Termos de indexação: Estresse oxidativo. Exercício. Superóxido dismutase. Zinco.

A B S T R A C T

The aim of this study is to provide information about the association between physical exercise, oxidative stress and zinc. The formation of reactive oxygen species during exercise may contribute to tissue and cell damage, hindering athletes' performance. Some minerals, such as zinc, mitigate these effects by acting as a cofactor of the enzyme superoxide dismutase and in the regulation of metallothionein synthesis - important proteins of the antioxidant defense system. During physical exercise, zinc compartmentalization may be impaired, that is, changes in the concentration of this mineral occur in cellular compartments. However, the mechanisms involved in the metabolism of zinc, as well as its improvement of physical performance, are not yet fully understood. Thus, further research on the distribution of zinc in organisms subjected to oxidative stress is needed, and also on how zinc deficiency affects the antioxidant capacity during exercise.

Indexing terms: Oxidative stress. Exercise. Superoxide dismutase. Zinc.

\footnotetext{
1 Universidade Federal do Piauí, Centro de Ciências da Saúde. Teresina, Piauí, Brasil.

2 Universidade Federal do Piauí, Centro de Ciências da Saúde, Departamento de Nutrição. Bloco 13, s/n., Campus Universitário Ministro Petrônio Portela, 64049-550, Ininga, Teresina, PI, Brasil. Correspondência para/Correspondence to: D.N. MARREIRO. E-mail: <dilina.marreiro@gmail.com>.
} 


\section{N T R O D U Ç Ã O}

Nas últimas décadas, tem havido um grande interesse por parte de vários pesquisadores em esclarecer o efeito do exercício físico sobre as alterações metabólicas e nutricionais. A produção de espécies reativas de oxigênio bem como o papel de substanciais antioxidantes têm sido os aspectos mais pesquisados.

A suplementação com nutrientes tem-se tornado cada vez mais comum na prática esportiva. Os minerais, em particular, têm sido consumidos de forma indiscriminada em função da sua relação com o desempenho em indivíduos fisicamente ativos ${ }^{1}$.

A atividade física favorece diversas adaptações fisiológicas, sendo necessários ajustes cardiovasculares e respiratórios para compensar e manter o esforço realizado. Durante o exercício físico, ocorre aumento do metabolismo energético com a formação excessiva de Espécies Reativas de Oxigênio (EROS). Essas espécies podem contribuir para danos tissulares e celulares, predispondo a lesões musculoesqueléticas e a prejuízo no desempenho do atleta ${ }^{2,3}$.

Nesses mecanismos, vários micronutrientes desempenham papel importante, entre eles o zinco, que participa da estrutura da enzima superóxido dismutase, sendo essencial para a função normal do sistema antioxidante endógeno, além de ser um potente estabilizador das membranas celulares, de proteínas estruturais e da sinalização celular ${ }^{4,5}$.

O zinco é um dos minerais de maior importância para o metabolismo. Dentre suas funções biológicas, ele é cofator de mais de 300 metaloenzimas, atuando em atividade catalítica de várias enzimas, tais como a anidrase carbônica, álcool desidrogenase e fosfatase alcalina, enzimas que participam do metabolismo de carboidratos, lipídeos e proteínas ${ }^{6}$. Algumas dessas enzimas estão envolvidas no sistema de defesa antioxidante durante o exercício, como, por exemplo, a superóxido dismutase ${ }^{7}$.
Diversos estudos evidenciaram alterações na compartimentalização do zinco em atletas, com valores desse mineral em parâmetros bioquímicos bastante controvertidos. Os estudos mostram concentrações reduzidas, normais ou elevadas de zinco no plasma, no soro e nos eritrócitos de atletas, que parecem ser dependentes do tipo de modalidade esportiva e do período da coleta do material biológico para análise do mineral ${ }^{8,9}$.

Os resultados de pesquisas conduzidas em atletas que realizam atividade anaeróbia mostram concentrações elevadas de zinco no plasma logo após a realização de exercício físico intenso, que têm sido atribuídas ao seu rápido extravasamento do tecido muscular para o fluido extracelular ${ }^{10}$. No entanto, a literatura também tem mostrado uma posterior redução do mineral nesse compartimento em função da sua redistribuição para os eritrócitos e para o fígado por meio das interleucinas circulantes, o que pode comprometer suas funções fisiológicas, como o sistema de defesa antioxidante ${ }^{11,12}$.

Paralelamente, em atletas e em indivíduos fisicamente ativos, têm sido evidenciadas alterações na atividade da enzima superóxido dismutase, tanto pelo aumento quanto pela redução na atividade dessa enzima ${ }^{13,14}$. Segundo Ji15, a atividade e a expressão dessa enzima parecem ser moduladas pela concentração de espécies reativas de oxigênio produzidas durante o exercício; conforme demonstrado pelo estudo de Schneider et al. ${ }^{16}$, há aumento da sua atividade como resultado da produção do radical superóxido.

Considerando-se, pois, as alterações bioquímicas e metabólicas do zinco, resultantes do exercício físico, bem como sua participação no sistema de defesa antioxidante e os mecanismos envolvendo esse oligoelemento e a melhora do desempenho físico em atletas, este estudo relata aspectos acerca do metabolismo do mineral, bem como de seu papel antioxidante sobre o estresse oxidativo gerado durante a realização do exercício físico. 


\section{M É T O D O S}

Esta revisão visa a trazer informações sobre os aspectos relacionados ao estresse oxidativo, metabolismo do zinco e de sua participação no desempenho físico. Nessa perspectiva, serão apresentados de forma específica os aspectos metabólicos e fisiológicos do zinco e o papel desse mineral na defesa antioxidante no exercício físico e ainda o efeito do exercício físico na compartimentalização do zinco.

O levantamento bibliográfico foi realizado nas bases de dados PubMed, SciELO, Lilacs, sem limite do ano de publicação, considerando os seguintes critérios de inclusão para as referências: (1) estudos que investigaram os aspectos metabólicos e fisiológicos do zinco e estresse oxidativo; (2) estudos que avaliaram a participação do zinco no estresse oxidativo e na defesa antioxidante em atletas. Além disso, os artigos foram selecionados quanto à originalidade e à relevância, considerando-se o rigor e a adequação do delineamento experimental, o número amostral e o tipo de medidas fisiológicas e de desempenho realizadas. Os trabalhos clássicos e recentes foram preferencialmente utilizados.

A estratégia de busca de fontes bibliográficas foi realizada em idiomas português e inglês com as seguintes palavras-chave: zinc, exercise, oxidative stress. O levantamento bibliográfico abrangeu os seguintes tipos de estudos: ensaios clínicos controlados randomizados ou quase-randomizados, coorte, estudo de caso-controle, série de casos e relato de caso, sendo pesquisados em 350 artigos, dos quais foram utilizados 62, que se relacionavam com esta pesquisa bibliográfica.

\section{Aspectos metabólicos e fisiológicos do zinco}

O zinco é o micronutriente intracelular mais abundante, sendo encontrado em todos os tecidos corpóreos. O conteúdo total de zinco no organismo varia de 1,5 a $2 \mathrm{~g}$ : cerca de $85 \%$ desse mineral estão concentrados nos músculos e nos ossos, e aproximadamente $80 \%$ presentes no sangue encontram-se nos eritrócitos ${ }^{6}$. Nos alimentos, o zinco está presente em maiores quantidades nas carnes vermelhas e nas ostras, sendo esses alimentos considerados as fontes mais ricas do mineral. Outros alimentos como ovos, carne de frango, leite e derivados, frutas oleaginosas - como as amêndoas -, e cereais integrais são boas fontes ${ }^{17}$. A recomendação atual de zinco varia de 6,8 a $8,5 \mathrm{mg} / \mathrm{dia}$, segundo a Estimated Average Requeriment (EAR), contida nas Dietary Reference Intakes (DRI), que refletem a quantidade do mineral suficiente para atingir as necessidades nutricionais de metade dos indivíduos saudáveis de determinado gênero e estágio de vida, sendo de 40mg/dia o nível máximo de ingestão tolerável do mineral ${ }^{18}$.

Esse mineral é um elemento traço essencial de grande importância na nutrição humana, pois atua como componente estrutural e funcional de várias metaloenzimas e metaloproteínas, participa de reações do metabolismo celular, incluindo processos fisiológicos tais como a função imune, defesa antioxidante, crescimento e desenvolvimento ${ }^{19}$.

O jejuno é a porção do intestino na qual a maior parte do zinco é absorvida e esse processo é dependente de sua concentração no lúmen. A captação do zinco pela superfície da borda em escova ocorre por meio de dois mecanismos de transporte: processo mediado por transportadores e por difusão simples, que variam em sua importância, conforme a quantidade presente na dieta. O mecanismo mediado por carreador predomina em situação de baixa concentração do mineral na dieta, enquanto a absorção por difusão simples é predominante quando seu consumo está elevado 20,21 .

A regulação homeostática do zinco, dentro das células intestinais, é regulada por duas proteínas: a proteína intestinal rica em cisteína (CRIP) e a metalotioneína ${ }^{22}$. Na deficiência de zinco, a proteína intestinal rica em cisteína, presente na mucosa intestinal, tem a função de carreador in- 
tracelular, ligando-se ao mineral quando ele atravessa o meio extracelular para o citosol do enterócito, passando por difusão em direção à membrana basolateral. A metalotioneína regula a ligação do zinco para a proteína intestinal rica em cisteína, o que inibe a absorção desse oligoelemento em condições de elevada concentração ${ }^{23}$.

As metalotioneínas desempenham um importante papel no transporte, estoque e distribuição do zinco. Esse micronutriente induz a síntese da metalotioneína, família de proteínas de baixo peso molecular (6000-7000kDa) e rica em resíduos de cisteína (25\%-30\%). Essas proteínas são encontradas no citosol de células eucarióticas especialmente no fígado, rins e intestino ${ }^{24}$.

A metalotioneína atua como marcador bioquímico que controla a concentração de zinco nas células. Em situações de elevadas concentrações desse mineral, a síntese de tioneína é estimulada por meio da sua ação sobre os fatores de transcrição zinco-dependentes, fazendo com que essa molécula se acople ao zinco para formar a metalotioneína. Dessa forma, essa proteína atua na proteção das células contra a toxicidade. $\mathrm{Na}$ presença de baixas concentrações na célula, o zinco é liberado da metalotioneina para ser utilizado por outras proteínas ${ }^{25}$.

Quanto aos aspectos moleculares da absorção de zinco, as pesquisas têm investigado a participação das proteínas transportadoras do mineral, as quais asseguram o carreamento de íons zinco através das membranas biológicas. Elas são especializadas na captação, efluxo e compartimentalização do zinco, contribuindo para a manutenção dos níveis intracelulares e para sua adequada distribuição nos tecidos por meio das membranas biológicas. Essas proteínas pertencem a duas famílias de genes: SLC30A e SLC39A, conhecidas como ZnT e Zip ${ }^{25,26}$.

Os genes envolvidos na síntese de proteínas transportadoras de zinco foram clonados recentemente. O primeiro gene a ser clonado foi o gene ZnT-1, sendo descoberto em 1995 por Palmiter \& Finley ${ }^{27}$. Os transportadores ZnT-1 estão associados com o efluxo de zinco nas células. Nos eritrócitos e nas células tubulares renais, esses transportadores localizam-se predominantemente na membrana basolateral, regulando a absorção e a reabsorção desse mineral, sendo encontrado também em vários outros tecidos, como no intestino, nos rins e no fígado. Além do ZnT-1, existem ainda o ZnT-2, que se localiza no intestino, rins e testículos; o ZnT-3, presente nos testículos e no cérebro; e o ZnT-4, presente em grandes quantidades nas glândulas mamárias e pode estar envolvido na secreção de zinco no leite ${ }^{25}$.

No estudo realizado por Liuzzi et al. ${ }^{28}$, foi observado que a suplementação com zinco aumenta a expressão do RNAm para ZnT-1 e ZnT-2 no intestino, fígado e rins, mostrando que a expressão desses transportadores ocorre em resposta às condições fisiológicas relativas ao zinco.

Os transportadores da família Zip são responsáveis pela captação intracelular desse mineral. O transportador Zip-1 está presente na maioria dos tecidos humanos, como o intestino delgado e o pâncreas. O Zip-3 está presente em maior concentração no baço e na medula óssea e em menor concentração no intestino delgado e fígado 20,27 .

Após a absorção, o zinco é liberado pela célula intestinal, passa para os capilares mesentéricos e é transportado no sangue portal, sendo captado pelo fígado e subsequentemente distribuído para os demais tecidos ${ }^{23}$. No plasma, o zinco é carreado por proteínas como a albumina, $\alpha^{2}$ macroglobulina e aminoácidos, sendo excretado principalmente pelo trato gastrointestinal ${ }^{29}$.

O zinco desempenha funções importantes em diversos processos biológicos do organismo, incluindo a síntese proteica, o metabolismo de DNA e RNA, metabolismo de carboidratos e lipídeos, metabolismo energético entre outras ${ }^{22}$. Uma das principais funções desse oligoelemento é sua atuação enzimática, seja na estrutura da enzima seja em sua ação regulatória ou catalítica no organismo ${ }^{21}$. Já foram identificadas mais de 300 metaloenzimas que necessitam de zinco para sua atividade, como a anidrase carbônica, fosfatase alcalina, carboxipeptidases, álcool desidrogenase, proteína quinase $C$, ácido ribonucleico polimerase, 
transcriptase reversa e a superóxido dismutase (tem ação antirradicais livres) ${ }^{6}$.

O zinco está envolvido na estabilização de membranas estruturais e na proteção celular, prevenindo a peroxidação lipídica. As propriedades antioxidantes desse mineral são explicadas pelo seu papel na regulação da síntese da metalotioneína, na estrutura da enzima superóxido dismutase e na proteção de grupamentos sulfidrila de proteínas de membranas celulares, onde promove a inibição da produção de espécies reativas de oxigênio por antagonismo com metais pró-oxidantes, como ferro e cobre. Estudos têm demonstrado que a fragilidade osmótica de eritrócitos está relacionada à função do mineral na membrana celular ${ }^{2,24}$.

A avaliação do estado nutricional relativo ao zinco tem sido realizada por meio de vários marcadores bioquímicos. O zinco plasmático, apesar de sua baixa sensibilidade, tem sido utilizado como biomarcador ${ }^{30}$. A concentração plasmática normal é acima de $70 \mu \mathrm{g} / \mathrm{dL}$, tendo uma média de aproximadamente $100 \mu \mathrm{g} / \mathrm{dL}^{31}$.

Já a medida da concentração do zinco eritrocitário não reflete mudanças recentes desse mineral no organismo, por isso é considerado um parâmetro mais sensível, apresentando valores médios de $42,2 \mu \mathrm{g} / \mathrm{g}$ de hemoglobina em indivíduos sadios ${ }^{31}$.

As manifestações de deficiência de zinco podem ser verificadas na expressão gênica de proteínas de grande importância ${ }^{22}$. Nesse contexto, o crescente avanço em estudos moleculares, como, por exemplo, a influência da metalotioneína e da proteína rica em cisteína na absorção desse mineral e a expressão de proteínas transportadoras de zinco, tem possibilitado um melhor entendimento do metabolismo desse mineral.

\section{Estresse oxidativo no exercício físico e zinco}

A atividade física favorece diversas adaptações fisiológicas, sendo necessários ajustes car- diovasculares e respiratórios para compensar e manter o esforço realizado². O exercício está associado ao aumento da formação de radicais livres, relacionado principalmente ao aumento do consumo de oxigênio pelos tecidos ativos ${ }^{32}$.

O oxigênio possui atividade fundamental no metabolismo celular aeróbio, pois esse elemento é necessário no processo de respiração celular que ocorre nas mitocôndrias das células a fim de gerar energia. Esse metabolismo pode conduzir à formação de radicais livres e ao estresse oxidativo, pois as espécies reativas de oxigênio semirreduzido, superóxido e peróxido de hidrogênio são produzidas pelas mitocôndrias durante a respiração celular ${ }^{33}$.

No exercício intenso, ocorre aumento de 10 a 20 vezes no consumo total de oxigênio do organismo e de 100 a 200 vezes na captação de oxigênio pelo tecido muscular, favorecendo a produção de radicais livres de oxigênio ${ }^{33}$. Além disso, a síntese dessas moléculas durante o exercício está associada ao aumento da liberação de catecolaminas e sua auto-oxidação, aumento do metabolismo dos prostanóides, das enzimas xantina-oxidases e NADPH oxidase, da oxidação de bases purínicas, e ainda distúrbio da homeostase do $\mathrm{Ca}^{2}$.

Em situações de exercícios extenuantes, como, por exemplo, em atividade aeróbia e anaeróbia, ocorre o aumento da produção de radicais livres, pois esta última impõe força nos músculos, podendo ocasionar danos às proteínas celulares. O treinamento de um judoca, por exemplo, pode ter duração de seis horas diárias, induzindo à produção de radicais livres. A elevada produção dessas moléculas promove um desequilíbrio entre o ataque oxidativo e o sistema de defesa antioxidante, contribuindo para a lesão muscular, compressão articular, inflamação, entre outras consequências ${ }^{34}$.

Vários estudos relacionaram o aumento da produção de espécies reativas de oxigênio com a instalação do processo de fadiga e lesão muscular após o exercício físico ${ }^{35,36}$. Em 2003, Quindry et al. ${ }^{36}$ verificaram valores médios elevados de ânios 
superóxidos após 2 horas da realização de uma sessão única de exercício máximo.

Num estudo realizado com animais, foi feita a análise de biomarcadores de condicionamento aeróbio e de estresse oxidativo em ratos treinados em natação. Os pesquisadores observaram uma diminuição da concentração de lactato sanguíneo naqueles treinados quando comparados com o grupo-controle, caracterizando um maior estresse oxidativo em ratos destreinados quando eles eram submetidos a um esforço ${ }^{37}$.

Nessa abordagem, várias pesquisas já demonstraram uma resposta adaptativa do organismo ao sistema antioxidante em atletas. Margaritis et al. ${ }^{38}$ verificaram que quanto mais alto o $\mathrm{VO}_{2 \max }$ em triatletas, mais elevada é a atividade da enzima glutationa peroxidase nos eritrócitos, contribuindo para a proteção do organismo ao dano na membrana celular. Diferentemente, Inal et al. ${ }^{39}$, analisando o metabolismo anaeróbio em exercício agudo de natação, não observaram a capacidade antioxidante após a produção de espécies reativas de oxigênio em atletas nadadores.

Nos anos recentes, muitos pesquisadores têm demonstrado interesse em elucidar a influência de minerais sobre o estresse oxidativo na atividade física. Essas pesquisas visam a reduzir os efeitos prejudiciais do excesso de espécies reativas de oxigênio, bem como melhorar a capacidade do sistema de defesa antioxidante dos atletas. Nesse sentido, a maioria dos estudos tem sido voltada para a contribuição de minerais traços, com ênfase no papel do zinco nesse processo ${ }^{7,8}$.

Muitos estudos têm demonstrado que as concentrações de zinco no plasma de indivíduos fisicamente ativos estão diminuídas durante o período de 2 a 24 horas após a realização do exercício intenso ${ }^{40}$. Peake et al. ${ }^{41}$ estudaram a concentração de zinco plasmático em corredores durante o período de treinamento intensivo por quatro semanas e demonstraram que os atletas apresentavam concentração de zinco plasmático significativamente menor do que indivíduos sedentários.
Na investigação realizada por Singh et al. ${ }^{42}$, foram verificados valores reduzidos da concentração plasmática de zinco em atletas corredores quando comparados com indivíduos sedentários. Tem-se evidenciado relação inversa entre a hipozincemia, a performance e a resistência muscular em atletas ${ }^{43}$.

A literatura tem mostrado alterações nos compartimentos do zinco em tipos diferentes de atividade física. No estudo conduzido por Tuya et al. ${ }^{12}$, foi evidenciado que, em treinamento aeróbio, os atletas apresentavam concentrações plasmáticas de zinco diminuídas quando comparados com indivíduos que praticavam atividade anaeróbia. Na opinião desses autores, o zinco atuaria como cofator de enzimas que participam do metabolismo energético e do sistema de defesa antioxidante em atividade física aeróbia. Portanto, o mineral seria mobilizado do plasma para exercer suas funções no metabolismo energético e na atividade da enzima superóxido dismutase intracelular.

Além disso, algumas investigações revelaram resultados da avaliação do zinco plasmático com valores médios elevados em atletas de corridas. Recentemente, no estudo de Oliveira et al. ${ }^{44}$, foram demonstradas concentrações plasmáticas de zinco superiores em adolescentes corredores, quando comparadas ao grupo-controle.

As pesquisas voltadas para esclarecer o metabolismo do zinco em atletas têm avaliado a compartimentalização do mineral antes e após a realização do exercício. Ainda em 1993, Bordin et al. ${ }^{45}$ encontraram aumento nas concentrações de zinco plasmático logo após o exercício intenso.

Posteriormente, Anderson et al. ${ }^{46}$ avaliaram o zinco no plasma em indivíduos treinados e sedentários, antes e após o exercício físico. Estes autores verificaram um aumento nas concentrações plasmáticas de zinco, logo após o exercício (fase aguda) em ambos os grupos. Após duas horas da realização da atividade, foi observada uma redução nos valores da concentração de zinco com diferença estatística significativa quando comparados aos valores iniciais. 
A magnitude do aumento das concentrações plasmáticas de zinco seguido de exercício intenso pode ser resultado do catabolismo muscular com liberação do mineral no fluido extracelular. Essas alterações metabólicas estão relacionadas à ocorrência de microlesões musculares devido ao impacto e à explosão no exercício, o que favorece a liberação do zinco do tecido muscular para o plasma ${ }^{8,40}$.

Nesse sentido, os mecanismos que participam das alterações no metabolismo do zinco têm sido atribuídos às concentrações aumentadas de interleucinas plasmáticas, sendo evidenciadas no processo inflamatório, no dano tissular e no exercício intenso. As interleucinas estimulam a captação do zinco do plasma para o fígado e eritrócitos e favorecem a síntese de metalotioneína (e possivelmente de superóxido dismutase e outras zincoproteínas), enzimas necessárias para a resposta de fase aguda 7,10 .

\section{Enzima superóxido dismutase, zinco e exercício físico}

O organismo possui mecanismos de defesa antioxidante que atuam para minimizar ou prevenir os efeitos causados pelos radicais livres, gerados pelo exercício intenso. Existem sistemas antioxidantes de defesa para proteção e sistemas de reparação que previnem o acúmulo de moléculas alteradas por oxidação ${ }^{47}$.

Os antioxidantes de defesa celular neutralizam a proliferação ou protegem a membrana das células da ação lesiva das espécies reativas de oxigênio. Esses compostos são classificados em sistemas antioxidantes intracelulares enzimáticos (catalase, superóxido dismutase e glutationa peroxidase) ou não enzimáticos, como as vitaminas hidrossolúveis (vitamina C), vitaminas lipossolúveis (vitamina E e carotenoides) e elementos de elevado peso molecular, como o zinco e o ferro ${ }^{48}$.

As enzimas superóxido dismutase, catalase e glutationa peroxidase representam a principal defesa endógena do organismo. A superóxido dis- mutase é uma enzima abundante do organismo e tem papel fundamental na defesa contra as espécies reativas de oxigênio. Essa enzima corresponde a uma família de proteínas com diferentes grupos prostéticos em sua composição. Nos sistemas eucariontes existem duas formas de superóxido dismutase: a forma $\mathrm{Cu} / \mathrm{Zn}$ superóxido dismutase, presente principalmente no citosol, e a manganês-superóxido dismutase, localizada primariamente na mitocôndria. Essa enzima ${ }^{49}$ possui papel antioxidante, pois catalisa a dismutação do radical superóxido em peróxido de hidrogênio $\left(\mathrm{H}_{2} \mathrm{O}_{2}\right)$ e oxigênio $\left(\mathrm{O}_{2}\right)$, na presença do próton $\mathrm{H}^{+}$.

Em 2002, Fiamoncini ${ }^{50}$ avaliou as concentrações eritrocitárias da enzima Cu/Zn superóxido dismutase em jogadores juniores de futebol e observou uma diminuição significativa da atividade da enzima após o exercício aeróbio. Entretanto, após a realização do exercício anaeróbio, o autor não verificou alterações nas concentrações eritrocitárias da Cu/Zn superóxido dismutase.

No estudo realizado por Groussard et al. ${ }^{51}$, foram determinados metabólicos do estresse oxidativo em sujeitos fisicamente ativos após a realização de exercício anaeróbio supramáximo. Os autores encontraram peroxidação lipídica elevada, bem como redução da atividade das enzimas antioxidantes glutationa peroxidase e Cu/Zn superóxido dismutase nas hemácias analisadas.

De forma semelhante, Koury et al. ${ }^{52}$, avaliando a atividade da enzima superóxido dismutase em atletas brasileiros de judô, 24 horas e 5 dias após a realização do exercício, verificaram uma redução significativa na atividade da enzima. No estudo de Margaritis et al. ${ }^{38}$, também foram verificados valores reduzidos da enzima superóxido dismutase quando avaliada em triatletas após o exercício físico.

As pesquisas realizadas têm demonstrado resultados controvertidos sobre o efeito do exercício na atividade das enzimas $\mathrm{Cu} / \mathrm{Zn}$ superóxido dismutase e glutationa peroxidase. Nesse sentido, diversos estudos demonstraram elevada atividade 
dessas enzimas após exercício em atletas submetidos à atividade de alta intensidade quando comparada à atividade dessas enzimas em indivíduos sedentários $^{53}$. De forma semelhante, em atletas de atividade de longa distância, como, por exemplo, o futebol, também têm sido evidenciados valores elevados da atividade das enzimas quando comparados aos valores do grupo-controle ${ }^{54}$.

Nesse contexto, alguns mecanismos têm sido propostos para esclarecer as alterações verificadas na atividade das enzimas antioxidantes em atletas. Alguns pesquisadores já demonstraram que o exercício extenuante agudo, crônico e moderado aumenta a produção de espécies reativas de oxigênio. Dessa forma, ocorre uma demanda metabólica e fisiológica para a resposta antioxidante, sendo verificado um aumento na atividade das enzimas antioxidantes tanto no músculo quanto no sangue induzido pelo treinamento físico ${ }^{14-16}$.

Recentemente, Oliveira et al. ${ }^{44}$ realizaram um estudo com adolescentes corredores e não verificaram diferença significativa na concentração da Cu/Zn superóxido dismutase nesses atletas quando comparados ao grupo-controle, mas encontraram correlação positiva entre as concentrações da enzima Cu/Zn superóxido dismutase e o zinco eritrocitário nos atletas corredores. Segundo os pesquisadores, ocorre uma demanda de zinco para a proteção das membranas de eritrócitos, causada pelo estresse oxidativo na prática esportiva.

Em 2000, o estudo de Selamoglu et al. ${ }^{55}$ mostrou diferenças adaptativas entre os exercícios aeróbios e anaeróbios, com a atividade da enzima glutationa peroxidase, em eritrócitos, aumentada nos corredores de longa distância quando comparada aos resultados obtidos em atletas levantadores de peso. Inal et al. ${ }^{39}$, analisando o metabolismo anaeróbio em exercício agudo de natação, observaram que a produção de radicais livres era superior à capacidade antioxidante. Entretanto, Subudhi et al. ${ }^{56}$ não verificaram em esquiadores alpinos de elite alterações nos marcadores de es- tresse oxidativo após treinamento, supondo então que esses atletas poderiam ter obtido uma adaptação positiva em seus mecanismos antioxidantes com o treinamento.

Koury et al. ${ }^{57}$ avaliaram a atividade da enzima Cu/Zn superóxido dismutase, a concentração da metalotioneína e o zinco eritrocitário de um nadador de elite e verificaram aumento significativo desses parâmetros após a suplementação com $22 \mathrm{mg}$ de gluconato de zinco durante 7 meses, com melhora da defesa antioxidante. De forma semelhante, também resultados de outros estudos têm sugerido a necessidade de maior quantidade de zinco na alimentação de atletas que praticam atividade de elevado impacto, como, por exemplo, a corrida e o triatlo ${ }^{58}$.

A prática de exercícios com treinamentos regulares e eficientes pode favorecer a redução da produção de espécies reativas de oxigênio, o que pode ocorrer em função do aumento da defesa antioxidante, evitando a instalação da fadiga muscular e o aparecimento de lesões musculares, distúrbios comuns em períodos longos de competição ${ }^{32}$.

Oliveira et al. ${ }^{59}$. Verificaram o efeito da suplementação de $22 \mathrm{mg}$ de gluconato de zinco na defesa antioxidante de jogadores de futebol que foram comparados a um grupo-controle. Os autores avaliaram as concentrações plasmáticas e eritrocitárias de zinco e a capacidade antioxidante antes e após 12 semanas de suplementação. Foi verificado um aumento do zinco plasmático em ambos os grupos, sendo maior no grupo suplementado. Entretanto, o zinco eritrocitário não foi alterado após o período da suplementação. Além disso, foi observada uma melhora da capacidade antioxidante nos atletas submetidos à suplementação.

Alguns autores sugerem que a suplementação de zinco também possa estar relacionada com o aumento da performance em atletas. Recentemente, em um estudo realizado por Ali et al. ${ }^{60}$, foi avaliada a força do tríceps e quadríceps em estudantes submetidas à suplementação com 
Quadro 1. Estudos que examinaram a relação entre estresse oxidativo, exercício, zinco e atividade da enzima superóxido dismutase.

\begin{tabular}{|c|c|c|c|}
\hline \multirow{2}{*}{ Estudo } & \multicolumn{3}{|c|}{ Zn e estresse oxidativo no exercício físico } \\
\hline & Amostra & Variável & Resultados \\
\hline Tuya et al. ${ }^{12}$ & $\begin{array}{l}\mathrm{n}=34 \text { atletas } \\
\text { (atv. aeróbia/anaeróbia) } \\
\mathrm{n}=16 \text { indivíduos ativos }\end{array}$ & Zn plasmático & $\begin{array}{l}\text { Reduziu o Zn no grupo de atletas em atividade aeróbia em } \\
\text { comparação com o grupo em atividade anaeróbia. Aumento } \\
\text { do Zn nos atletas em relação ao controle. }\end{array}$ \\
\hline Peake et al. ${ }^{41}$ & $\begin{array}{l}n=10 \text { corredores } \\
n=7 \text { sedentários }\end{array}$ & Zn plasmático & $\begin{array}{l}\text { Reduziu os valores de } Z n \text { nos corredores em relação ao con- } \\
\text { trole. }\end{array}$ \\
\hline Singh et al. ${ }^{42}$ & $\begin{array}{l}\mathrm{n}=17 \text { corredores } \\
\mathrm{n}=17 \text { sedentários }\end{array}$ & Zn plasmático & $\begin{array}{l}\text { Reduziu os valores de Zn nos corredores em relação ao con- } \\
\text { trole. }\end{array}$ \\
\hline Van Loan et al. ${ }^{43}$ & $\mathrm{n}=8$ indivíduos normais & $\begin{array}{l}\text { Zn plasmático } \\
\text { Força muscular }\end{array}$ & $\begin{array}{l}\text { Diminuição da capacidade total de trabalhomuscular com a } \\
\text { depleção aguda de Zn. }\end{array}$ \\
\hline Oliveira et al. ${ }^{44}$ & $\begin{array}{l}\mathrm{n}=18 \text { corredores } \\
\mathrm{n}=15 \text { sedentários }\end{array}$ & Zn plasmático & $\begin{array}{l}\text { Aumento de Zn após } 24 \text { h do exercício nos corredores em re- } \\
\text { lação aos sedentários. }\end{array}$ \\
\hline Bordin et al. ${ }^{45}$ & $\mathrm{n}=19$ indivíduos normais & Zn plasmático & $\begin{array}{l}\text { Aumento de Zn logo após o exercício ediminuição após 30min } \\
\text { de repouso. }\end{array}$ \\
\hline Anderson et al. ${ }^{46}$ & $\begin{array}{l}\mathrm{n}=8 \text { corredores } \\
\mathrm{n}=5 \text { sedentários }\end{array}$ & Zn plasmático & $\begin{array}{l}\text { Aumento de Zn logo após o exercício ediminuição após 2h. } \\
\text { Valores semelhantes em ambos os grupos. }\end{array}$ \\
\hline \multirow{2}{*}{ Estudo } & \multicolumn{3}{|c|}{ Enzima superóxido dismutase e exercício físico } \\
\hline & Amostra & Variável & Resultados \\
\hline Margaritis et al. ${ }^{38}$ & $\mathrm{n}=12$ triatletas & SOD & Diminuição da atividade da enzima após o exercício físico. \\
\hline Inal et al. ${ }^{39}$ & $\begin{array}{l}\mathrm{n}=10 \text { nadadores } \\
\text { (exercício aeróbio) } \\
\mathrm{n}=9 \text { nadadores } \\
\text { (exercícios anaeróbio) }\end{array}$ & $\begin{array}{l}\text { Lactato } \\
\text { GPx } \\
\text { CAT }\end{array}$ & $\begin{array}{l}\text { Aumento do lactato após o } 1^{\circ} \text { minuto de exercício. Aumento } \\
\text { do GPx e CAT no } 1^{\circ} \text { minuto e diminuição posterior. }\end{array}$ \\
\hline Oliveira et al. ${ }^{44}$ & $\begin{array}{l}\mathrm{n}=18 \text { corredores } \\
\mathrm{n}=15 \text { sedentários }\end{array}$ & SOD & $\begin{array}{l}\text { Não houve diferença significativa entre os atletas e o grupo- } \\
\text { controle. }\end{array}$ \\
\hline Fiamocini50 & $\mathrm{n}=18$ jogadores de futebol & SOD & $\begin{array}{l}\text { Diminuição da enzima após exercício aeróbio. } \\
\text { Sem alteração após exercícios anaeróbio. }\end{array}$ \\
\hline Koury et al. ${ }^{52}$ & $\mathrm{n}=7$ atletas de judô & SOD & Diminuição da enzima 24 horas e 5 dias apóso exercício. \\
\hline Ørtenbland et al. ${ }^{53}$ & $\begin{array}{l}\mathrm{n}=8 \text { treinados } \\
\mathrm{n}=8 \text { não treinados }\end{array}$ & $\begin{array}{l}\text { SOD } \\
\text { GPX } \\
\text { GR }\end{array}$ & $\begin{array}{l}\text { Aumento das enzimas após exercício anaeróbio nos indivídu- } \\
\text { os treinados em relação aos destreinados. }\end{array}$ \\
\hline Brites et al. ${ }^{54}$ & $\begin{array}{l}\mathrm{n}=30 \text { atletas de futebol } \\
\mathrm{n}=12 \text { sedentários }\end{array}$ & SOD & $\begin{array}{l}\text { Aumento da enzima após exercício nos atletas em relação } \\
\text { aos sedentários. }\end{array}$ \\
\hline Koury et al. ${ }^{54}$ & $\mathrm{n}=1$ nadador de elite & $\begin{array}{l}\text { SOD } \\
\text { Zn } \\
\text { Metalotioneína }\end{array}$ & $\begin{array}{l}\text { Aumento das variáveis após a suplementação com } 22 \mathrm{mg} \text { de } \\
\text { gluconato de Zn por } 7 \text { meses. }\end{array}$ \\
\hline Oliveira et al. ${ }^{59}$ & $\begin{array}{l}\mathrm{n}=26 \text { jogadores de futebol } \\
\mathrm{n}=21 \text { sedentários }\end{array}$ & $\begin{array}{l}\text { Zn plasmático } \\
\text { Zn eritrocitário }\end{array}$ & $\begin{array}{l}\text { Aumento do Zn plasmático após suplementação de } 22 \mathrm{mg} \text { de } \\
\text { gluconato de Zn, sendo maior no grupo de atletas. } \\
\text { Não houve alteração do Zn eritrocitário. Houve melhora da } \\
\text { capacidade antioxidante. }\end{array}$ \\
\hline Ali et al. ${ }^{60}$ & $\begin{array}{l}\mathrm{n}=12 \text { estudantes casos } \\
\mathrm{n}=12 \text { estudantes- controles }\end{array}$ & $\begin{array}{l}\text { Força do tríceps } \\
\text { e quadríceps }\end{array}$ & $\begin{array}{l}\text { Melhora da função muscular após } 8 \text { semanas de suplemento } \\
\text { de } 25 \mathrm{mg} / \text { dia de zinco. }\end{array}$ \\
\hline Brilla et al. ${ }^{61}$ & $\begin{array}{l}n=12 \text { jogadores casos } \\
n=15 \text { jogadores controles }\end{array}$ & Força muscular & $\begin{array}{l}\text { Melhora da potência dos músculos do grupo suplementado } \\
\text { com } 30 \mathrm{mg} / \text { dia de } Z \mathrm{n} \text {. }\end{array}$ \\
\hline VanLoan et al. ${ }^{62}$ & $\mathrm{n}=8$ indivíduos sexo masculino & $\begin{array}{l}\text { Função muscular } \\
\text { Zn plasmático }\end{array}$ & $\begin{array}{l}\text { Diminuição da capacidade de trabalho total para os músculos } \\
\text { extensores de joelho e flexores e extensores do ombro com o } \\
\text { esgotamento agudo de Zn. }\end{array}$ \\
\hline
\end{tabular}

Zn: zinco; SOD: enzima superóxido dismutase; CAT: enzima glutationa catalase; GPx: glutationa peroxidase; GR: glutationa reduzida. 
o mineral e comparadas ao grupo-controle. De acordo com os resultados, após o uso do suplemento com $25 \mathrm{mg} /$ dia de gluconato de zinco durante 8 semanas, houve melhora da função muscular nos atletas que realizaram o exercício físico.

Em outro estudo realizado com jogadores de futebol, foi observada diferença estatística $(p<0,001)$ na potência dos músculos do grupo suplementado com zinco, quando comparada com a do grupo-controle ${ }^{61}$. Concomitante a esse estudo, VanLoan et al. ${ }^{62}$ verificaram em sua pesquisa relação inversa entre a depleção aguda de zinco e a capacidade de trabalho musculoesquelético.

Diversas investigações têm sido realizadas na perspectiva de esclarecer o estado nutricional relativo ao zinco em atletas, os mecanismos que favorecem a produção de espécies reativas de oxigênio após o exercício, bem como a participação no sistema de defesa antioxidante. No entanto, o entendimento sobre as alterações na distribuição de zinco e o papel desse mineral e da enzima Cu/Zn superóxido dismutase na defesa antioxidante em indivíduos fisicamente ativos ainda são escassos (Quadro 1).

\section{CONSI DERAÇÕ ES FIN A IS}

Existem evidências experimentais que demonstram alterações na distribuição do zinco em atletas, bem como distúrbios bioquímicos e metabólicos decorrentes da deficiência desse mineral. Várias pesquisas mostram os resultados promissores da suplementação com zinco na melhora do sistema de defesa antioxidante em atletas que apresentam deficiência. Novos estudos sobre os mecanismos de interação do zinco diretamente com as enzimas que participam do sistema de defesa antioxidante poderão fornecer bases para o entendimento bioquímico da interação desse mineral com as alterações resultantes do estresse oxidativo. O desdobramento desse conhecimento poderá nortear outros ensaios clínicos para estabelecer o potencial terapêutico do zinco sobre o sistema de defesa antioxidante em atletas.

\section{COLABORADORES}

L.S. ANDRADE participou da sua concepção e da sua redação. D.N. MARREIRO contribuiu como orientadora do trabalho e participou da concepção, da formatação do conteúdo e da correção da redação.

\section{REFER Ê N CIAS}

1. Lukaski HC. Vitamin and mineral status: effects on physical performance. Nutrition. 2004; 20(7-8): 632-44. doi: 10.1016/j.nut.2004.04.001.

2. Koury JC, Donangelo CM. Zinco, estresse oxidativo e atividade física. Rev Nutr. 2003; 16(4):433-41. doi: 10.1590/S1415-52732003000400007.

3. Cruzat VF, Rogero MM, Borges MC, Tirapegui J. Aspectos atuais sobre estresse oxidativo, exercícios físicos e suplementação. Rev Bras Med Esporte. 2007; 13(5):336-42. doi: 10.1590/S1517-869220 0700050001.

4. Clarkson PM, Thompson HS. Antioxidants: what role do they play in physical activity and health? Am J Clin Nutr. 2000; 72(2):637-47.

5. Micheletti A, Rossi R, Rufini S. Zinc status in athletes: relation to diet and exercise. Sports Med. 2001; 31(8):577-82.

6. Mccall KA, Huang C, Fierke CA. Function and mechanism of zinc metalloenzymes. J Nutr. 2000; 130:S1437-46.

7. Lukaski HC. Magnesium, zinc, and chromium nutriture and physical activity. Am J Clin Nutr. 2000; 72(2):585-93.

8. Koury JC, Oliveira Júnior AVD, Portella ES, Oliveira CFD, Lopes GC, Donangelo CM. Zinc and copper biochemical indices of antioxidant status in elite athletes of different modalities. Int J Sport Nutr Exerc Metabol. 2004; 14(3):358-72.

9. Saliba LF, Tramonte VLCG, Faccin GL. Zinco no plasma e eritrócito de atletas profissionais de uma equipe feminina brasileira de voleibol. Rev Nutr. 2006; 19(5): 581-90. doi: 10.1590/S1415-5273200600 0500006.

10. Lukaski HC. Micronutrients (Mg, Zn, Cu): are mineral supplements needed for athletes? Int J Sport Nutr. 1995; 5:574-83.

11. Lukaski H, Hoverson BS, Gallagher SK, Bolonchuk WW. Physical training and copper, iron, and zinc status of swimmers. Am J Clin Nutr. 1990; 51(6): 1093-9.

12. Tuya IR, Gil PE, Mariño MM, Carra RM, Misiego AS. Evaluation of the influence of physical activity on the plasma concentrations of several trace 
elements. Eur J Appl Physiol. 1996; 73(3-4):299-303. doi: 10.1007/BF02425490.

13. Metin G, Atukeren P, Alturfan AA, Gulyasar T, Kaya M, Gumustas MK. Lipid peroxidation, erythrocyte superoxide-dismutase activity and trace metals in young male footballers. Yonsei Med. J. 2003; 44(6): 979-86.

14. Smolka MB, Zoppi CC, Alves AA, Silveira L R, Marangoni S, Pereira-Da-Silva L. et al. HSP72 as a complementary protection against oxidative stress induced by exercise in the soleus muscle of rats. Am J Physiol Regul Integr Comp Physiol. 2000; 279(5):1539-45.

15. J LL. Exercise induced modulation of antioxidant defense. Ann N Y Acad Sci. 2002; 959:82-92. doi: 10.1111/j.1749-6632.2002.tb02085.x.

16. Schneider CD, Barp J, Ribeiro JL, Belló-Klein A, Oliveira AR. Oxidative stress after three different intensities of running. Appl Physiol Nutr Metab. 2005; 30(6):723-34. doi: 10.1139/h05-151.

17. Sandström B. Bioavailability of zinc. Eur J Clin Nutr. 1997; 51(1):17-9.

18. Food and Nutrition Board. Dietary reference intakes for vitamin A, vitamin K, arsenic, boron, chromiun, copper, iodine, iron, manganese, molybdnum, nickel, silicon, vanadium, and zinc. Washington: National Academy of Sciences; 2001.

19. Szckurek El, Bjornsson CS, Taylor CG. Dietary zinc deficiency and repletion modulate metallothionein immunolocalization and concentration in small intestine and liver of rats. J Nutr. 2001; 131:2132-8.

20. Cousins RJ, McMahon RJ. Integrative aspects of zinc transporters. J Nutr. 2000; 130(5):1384-7.

21. Salgueiro MJ, Zubillaga M, Lysionek A, Sarabia MI, Caro R, De Paoli T, et al. Zinc as an essential micronutrient: a review. Nutr Res. 2000; 20(5): 737-55. doi: 10.1016/S0271-5317(00)00163-9.

22. Henriques GS, Hirata MH, Cozzolino SNF. Aspectos recentes da absorção e Biodisponibilidade do zinco e suas correlações com a fisiologia da isoforma testicular da enzima conversora de angiotensina. Rev Nutr. 2003; 16(3):333-45. doi: 10.1590/\$1415-5 2732003000300011.

23. Mafra D, Cozzolino SMF. Importância do zinco na nutrição humana. Rev Nutr. 2004; 17(1):79-87. doi: 10.1590/S1415-52732004000100009.

24. Powell SR. The antioxidant properties of zinc. J Nutr. 2000; 130(5):1447-54.

25. Seve M, Chimienti F, Devergnas S, Favier A. In silico identification and expression of SLC30 family genes: an expressed sequence tag data mining atrategy for the characterization of zinc transporters tissue expression. BMC Genomics. 2004; 5(1):32. doi: 10.1186/1471-2164-5-32.b.
26. Dervigiliis C, Zalewski PD, Perozzi G, Murgia C. Zinc fluxes and zinc transporter genes in chronic diseases. Mutat Res. 2007; 622(1-2):84-93.

27. Palmiter RD, Findley SD. Cloning and functional characterization of a mammalian zinc transporter that confers resistance to zinc. EMBO J. 1995; 14(4): 639-49.

28. Liuzzi JP, Blanchard RK, Cousins RJ. Differenctial regulation of zinc transporter 1,2 and 4 mRNA expression by dietary zinc in rats. J Nutr. 2001; 131 : 46-52.

29. Mcmahon RJ, Cousins RJ. Mammalian zinc transporters. J Nutr. 1998; 128(4):667-70.

30. Hambidge M. Biomarkers of trace mineral intake and status. J Nutr. 2003; 133(3):948-55.

31. Gibson RS. Principles of nutritional assessment. New York: Oxford University; 1990. p.543-53.

32. Zoppi CC, Antunes-Neto J, Catanho FO, Goulart LF, Mota MN, Vaz De Macedo D. Alterações em biomarcadores de estresse oxidativo, defesa antioxidante e lesão muscular em jogadores de futebol durante uma temporada competitiva. Rev Paul Educ Fís. 2003; 17(2):119-30.

33. Urso ML, Clarkson PM. Oxidative stress, exercise, and antioxidant supplementation. Toxicology. 2003; 189(1):41-54. doi: 10.1016/S0300-483X(03) 00151-3.

34. Smith MA, Reid MB. Redox modulation of contractile function in respiratory and limb skeletal muscle. Resp Physiol Neurobiol. 2006; 151(2-3): 229-41.

35. Barclay JK, Hansel M. Free radicals may contribute to oxidative muscle fatigue. Can J Phys Pharm. 1990; 69(2): 279-84. doi: 10.1139/y91-043.

36. Quindry JC, Stone WL, King J, Broeder CE. The effects of acute exercise on neutrophils and plasma oxidative stress. Med Sci Sports Exer. 2003; 35(7): 1139-45.

37. Prada FJA, Voltarelli FA, Oliveira CAM, Gobatto CA, Macedo DV, Mello MAR. Condicionamento aeróbio e estresse oxidativo em ratos treinados por natação em intensidade equivalente ao limiar anaeróbio. Rev Bras Ciênc Mov. 2004; 12(2):29-34.

38. Margaritis F, Tessier F, Richard MJ, Marconnet P. No evidence of oxidative stress after a triatlon race in highly trained competitors. Int J Sports Med. 1997; 18(3):186-190. doi: 10.1055/s-2007-972617.

39. Inal M, Akyüz F, Turgut A, Getsfrid WM. Effect of aerobic and anaerobic metabolism on free radical generation swimmers. Med Sci Sports Exer. 2001; 33(4):564-67.

40. Cordova A, Mon-Alvarez M. Behaviour of zinc in physical exercise: a special reference to immunity 
and fatigue. Neurosci Biobehav Rev. 1995; 19(3): 439-45. doi: 10.1016/0149-7634(95)00002-V.

41. Peake JM, Gerrard DF, Griffin JFT, Plasma zinc and immune markers in runners in response to a moderate increase in training volume. Int J Sports Med. 2003; 24(3):212-6. doi: 10.1055/s-2003-39 094.

42. Singh A, Evans P, Gallagher KL, Deuster P. Dietary intakes ad biochemical profiles of nutritional status of ultramarathoners. Med Sci Sports Exerc. 1993; 25(3):328-34.

43. Van Loan MD, Sutherland B, Lowe NM, Turnland $J R$, King JC. The effects of zinc depletion on peak force and total work of knee and shoulder extensor and flexor muscles. Int J Sport Nutr. 1999; 9(2): 125-35.

44. Oliveira KJF, Koury JC, Donangelo CM. Micronutrientes e capacidade antioxidante em adolescentes sedentários e corredores. Rev Nutr. 2007; 20(2): 171-9. doi: 10.1590/S1415-52732007000200006.

45. Bordin D, Sartorelli L, Bonanni G, Mastrogiacomo I, Scalco E. High intensity physical exercise induced effects on plasma levels of copper and Zinc. Biol Trace Elem Res. 1993; 36(2):129-34. doi: 10.1007/B F02783171.

46. Anderson RA, Bryden NA, Polansky MM, Deuster PA. Acute exercise effects on urinary losses and serum concentrations of copper and zinc of moderately trained and untrained men consuming a controlled diet. Analyst. 1995; 120(3):867-70. doi: 10.1039/AN9952000867.

47. Goode HF, Webster NR. Free radicals and antioxidants in sepsis. Crit Care Med. 1993; 21(11): 1770-6. doi: 10.1016/j.intimp.2004.01.020.

48. Atalay M, Laaksonen DE, Khanna S, KalisteKorhonen E, Hanninen O, Sen CK. Vitamin E regulates changes in tissue antioxidants induced by fish oil and acute exercise. Med Sci Sports Exerc. 2000; 32(3):601-7.

49. Acharya J, Punchard NA, Taylor JA, Thompson RP, Pearson TC. Red cell lipid peroxidation and antioxidant enzymes in iron deficiency. Eur J Haematol. 1991; 47(4): 287-91. doi: 10.1111/j.16 00-0609.1991.tb01573.

50. Fiamoncini RL. Análise do estresse oxidativo em jogadores juniores de futebol: comparação entre pré e pós-exercício aeróbio e anaeróbio [mestrado]. Santa Catarina: Universidade Federal de Santa Catarina; 2002.

51. Groussard C, Rannou-Bekono F, Machefer G, Chevanne M, Vincent S, Sergent O, et al. Changes in blood lipid peroxidation markers and antioxidants after a single sprint anaerobic exercise.
Eur J Appl Physiol. 2003; 89(1):14-20. doi: 10.1007/ s00421-002-0767-1.

52. Koury JC, Oliveira CF, Portella ES, Junior AVO. Effect of the period of resting in elite judo athletes. Biol Trace Elem Res. 2005; 107(3):201-11. doi: 10.1385/B TER:107:3:201.

53. Ørtenbland N, Madsen K, Mogens SD. Antioxidant status and lipid peroxidation after short-term maximal exercise in trained and untrained humans. Am J Physiol Regul Integr Comp Physiol. 1997; 272(4):1258-63.

54. Brites FD, Evelson PA, Christiansen MG, Nicol MF, Basilico MJ, Wikinski RW, et al. Soccer players under regular training show oxidative stress but an improved plasma antioxidant status. Clin Sci. 1999; 96(4):381-5.

55. Selamoglu S, Turgay F, Kayatekin BM, Günenc S, Yslegen $C$. Aerobic and anaerobic training effects on the antioxidant enzymes of the blood. Acta Physiol Hung. 2000; 87(3):267-73.

56. Subudhi AW, Davis SL, Kipp RW, Askew EW. Antioxidant status and oxidative stress in elite alpine ski racers. Int J Sport Nutr Exerc Metab. 2001; 11(1): 32-41.

57. Koury JC, Oliveira CF, Aragdo MV, Donangelo CM. Metallothionein and superoxide dismutase in erythrocytes are influenced by sport impact in anaerobic modalities. FASEB J. 2003; 17:A1129.

58. Peres PM, Koury JC. Zinco, imunidade, nutrição e exercício. Ceres: Nutr Saúde. 2006; 1(1):9-18.

59. Oliveira KJF, Donangelo CM, Oliveira JAV, Silveira CLPS, Koury JC. Effect of zinc supplementation on the antioxidant, copper, and iron status of physically active adolescents. Cell Biochem Funct. 2009; 27(3): 162-6. doi: 10.1002/cbf.1550.

60. Ali PN, Hanachi P, Golkhoo S. Effect of Zinc Supplement on the Upper and Lower Trunk Strength on Athletics Women. Res J Int Stud. 2009; 9(1):59-64.

61. Brilla LR, Conte V. Effects of a novel zincmagnesium formulation on hormones and strength. J Exerc Physiol Online. 2000; 3(4):26-36.

62. VanLoan MD, Sutherland B, Lowe NM, Turnland JR, King JC. The effects of zinc depletion on peak force and total work of knee and shoulder extensor and flexor muscles. Int J Sport Nutr. 1999; 9(2): 125-35.

Recebido em: 25/11/2009

Versão final reapresentada em: 3/1/2011 Aprovado em: 31/1/2011 